\title{
Radial Growth Response of Larix gmelinii to Climate along a Latitudinal Gradient in the Greater Khingan Mountains, Northeastern China
}

\author{
Yangao Jiang ${ }^{1,2}$, Junhui Zhang ${ }^{1, *}$, Shijie Han ${ }^{1, *}$, Zhenju Chen ${ }^{3}$, Heikki Setälä ${ }^{4}$, Jinghua Yu ${ }^{1}$, \\ Xingbo Zheng ${ }^{1}$, Yingtao Guo ${ }^{5}$ and Yue $\mathrm{Gu}^{1,2}$ \\ 1 Institute of Applied Ecology, Chinese Academy of Sciences, Shenyang 110016, China; \\ jiangyangao-jyg@163.com (Y.J.); yujh@iae.ac.cn (J.Y.); zhxb@iae.ac.cn (X.Z.); guyue740147940@126.com (Y.G.) \\ 2 University of Chinese Academy of Sciences, Beijing 100049, China \\ 3 College of Forestry, Shenyang Agricultural University, Shenyang 110866, China; zhenjuchen@hotmail.com \\ 4 Department of Environmental Sciences, University of Helsinki, Lahti 15140, Finland; \\ heikki.setala@helsinki.fi \\ 5 Key Laboratory of Forest Plant Ecology, Northeast Forestry University, 26 Hexing Road, Harbin 150040, \\ China; gyingtao@163.com \\ * Correspondence: jhzhang@iae.ac.cn (J.Z.); hansj@iae.ac.cn (S.H.); Tel.: +86-24-8397-0443 (J.Z. \& S.H.)
}

Academic Editor: Timothy A. Martin

Received: 12 November 2016; Accepted: 17 November 2016; Published: 28 November 2016

\begin{abstract}
To explore how climatic factors influence tree growth within the context of global climate changes, we used a dendroclimatological analysis to understand the response of Larix gmelinii to climatic variations along a broad latitudinal gradient from $47.27^{\circ}$ to $52.66^{\circ} \mathrm{N}$ in the Greater Khingan Mountains of Northeastern China. The growth-limiting climate factors and a detailed association between radial growth and climate were identified along the gradient using redundancy analysis (RDA) and standard correlation function analysis over the period 1960-2013. The results showed that temperatures during current June to July represented the most important factor affecting tree radial growth in the study area. Across all studied latitudes, Larix gmelinii growth might be decreasing in radial growth due to higher monthly maximum temperature (Tmax) and monthly mean temperatures $(\mathrm{Tm})$ in the current June, especially for the stands at low and middle latitudes. With continued warming, Larix gmelinii radial growth at high latitudes (e.g., Mangui (MG) and Mohe (MH)) might be reduced by warmer temperatures in July. In addition, Larix gmelinii might be decreasing in radial growth from decreasing precipitation. Our results show that there is a decreasing trend in Larix gmelinii radial growth under the observed general increase of temperatures in the Greater Khingan Mountains in recent years.
\end{abstract}

Keywords: boreal forest; dendroecology; tree-ring growth; climate warming

\section{Introduction}

The stem radial growth of trees in any year integrates the effects of the climate during the previous and current year [1-4]. Tree radial growth is influenced by environmental factors (e.g., temperature, precipitation, and competition) and conditions within the individual tree [1,2]. Tree-ring records are often used to investigate the responses of tree growth to historical climate variations, to predict the effects of future climate change on tree growth, and to understand the spatial and temporal patterns of tree-growth variability of forest ecosystems [5-7]. Therefore, tree-ring records can increase our capacity to predict potential changes in forest structure and composition, as well as provide important information on natural resource management [8-12]. 
Larix gmelinii (Rupr.) is one of the most economically important species in boreal forests [13]. It is a deciduous needleleaf conifer that is adapted to growing in very harsh climates and is widely distributed over a range from $40^{\circ} \mathrm{N}$ to $72^{\circ} \mathrm{N}$ and $110^{\circ} \mathrm{E}$ to $130^{\circ} \mathrm{E}$ [13]. It is the dominant tree species in the Greater Khingan Mountains forest ecosystem in northern China [14,15].

Modeling studies predict that L. gmelinii growth will decrease rapidly in China due to the predicted increases in temperature [16-19] and decreases in precipitation [17]. However, empirical/observational evidence of such declines in growth at the regional scale is lacking in this region. Only a few investigations on L. gmelinii radial growth response to climate variation have been conducted at a small number of distinct locations in the northern part of the Greater Khingan Mountains during the past few decades [20-22]. The aims of this paper are (1) to identify the spatial pattern of the radial growth-climate relationship of Larix gmelinii and (2) to identify the dominant climatic factors affecting growth over a large latitudinal range $\left(47.27^{\circ}\right.$ to $\left.52.66^{\circ} \mathrm{N}\right)$ in the western Greater Khingan Mountains, China.

\section{Materials and Methods}

\subsection{Study Area}

The study was conducted along a latitudinal gradient in eastern Inner Mongolia and Heilongjiang Province of Northeastern China. Tree-ring samples were collected at seven sites: Mohe (MH), Mangui (MG), Moerdaoga (MEDG), Yitulihe (YTLH), Wuerqihan (WEQH), Boketu (BKT), and Aershan (AES), ranging from $120.30^{\circ}$ to $122.31^{\circ} \mathrm{E}$ and $47.27^{\circ}$ to $52.66^{\circ} \mathrm{N}$ (Figure 1). All of the selected stands of Larix gmelinii were naturally established, with no evidence of recent disturbance. To minimize the effects of local terrain and microenvironmental factors on tree growth, the topography of all selected plots was uniform and flat, with an elevation range of $908 \mathrm{~m}$ to $1018 \mathrm{~m}$ and a southern aspect with the slope ranging from 0 to 20 degrees (Table 1). Further, all sites except AES were located at the peaks of the local mountains. The sampling sites cover almost the entire native latitudinal distribution range of Larix gmelinii in China. The climate in the study region is continental monsoon characterized by a windy spring, a short, warm, and humid summer, and a long, dry, and cold winter. The mean annual precipitation (1960-2013) of the study sites ranged between 415 and $488 \mathrm{~mm}$ (Figure 2), with the period between April and September accounting for $\sim 88 \%-90 \%$ of the annual precipitation [23]. The mean annual temperature ranged from $-5.8^{\circ} \mathrm{C}$ to $-1.8^{\circ} \mathrm{C}$ [23]. Soil type varies among the seven sites, being mostly brown coniferous forest soils, chernozem soil, and grey forest soil, with a depth of 8 to $100 \mathrm{~cm}$ (Table 1).

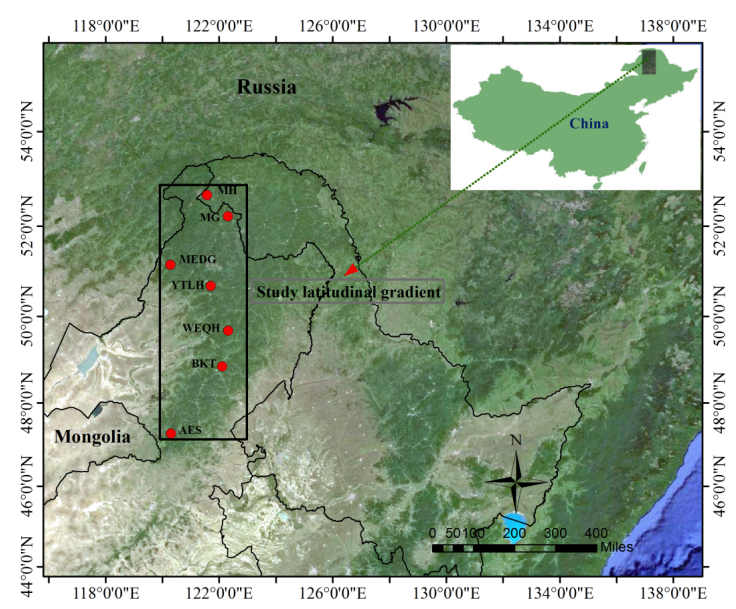

Figure 1. Map showing the locations in China where Larix gmelinii tree-ring samples were collected (red-filled circles). Abbreviations for our sampling sites are AES (Aershan), BKT (Boketu), WEQH (Wuerqihan), YTLH (Yitulihe), MEDG (Moerdaoga), MG (Mangui), and MH (Mohe). 
Table 1. Characteristics of the sampling sites in the western Greater Khingan Mountains, China.

\begin{tabular}{cccccccc}
\hline Site Code & MH & MG & MEDG & YTLH & WEQH & BKT & AES \\
\hline Long. (E) & 121.57 & 122.3 & 120.28 & 121.7 & 122.31 & 122.1 & 120.3 \\
Lat. (N) & 52.66 & 52.21 & 51.15 & 50.68 & 49.68 & 48.85 & 47.27 \\
Elev. (a.s.l.) & 908 & 931 & 971 & 908 & 988 & 996 & 1018 \\
Slope & 10 & 10 & 0 & 12 & 20 & 0 & 0 \\
Aspect & South & South & South & South & South & South & South \\
Soil depth $(\mathrm{cm})$ & 10 & 50 & 10 & 20 & 100 & 10 & 100 \\
Soil N content $(\mathrm{g} / \mathrm{kg})$ & 0.12 & 0.25 & 0.19 & 0.29 & 0.34 & 0.18 & 0.42 \\
Annual mean temperature $\left({ }^{\circ} \mathrm{C}\right)$ & -5.8 & -5.6 & -4.4 & -4.9 & -3.4 & -1.8 & -2 \\
Annual total precipitation $(\mathrm{mm})$ & 426 & 453 & 415 & 454 & 476 & 488 & 433 \\
\hline
\end{tabular}

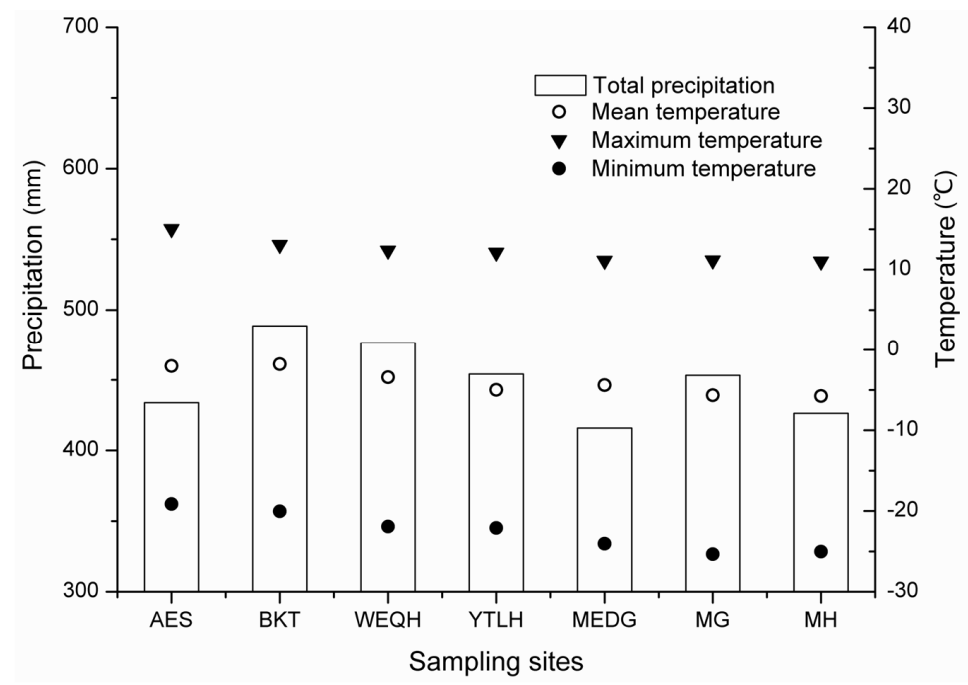

Figure 2. Annual maximum, mean, and minimum temperatures, and mean annual total precipitation from 1960 to 2013 along the latitudinal gradient from $47.27^{\circ}$ to $52.66^{\circ} \mathrm{N}$ (from AES to MH) at the seven sites in the Greater Khingan Mountains of the western Chinese boreal forest.

\subsection{Tree-Ring Sampling and Chronology Development}

Each site consisted of three stands. Twenty-one forested stands were sampled in 2013 and 2014. Two tree-ring increment cores per tree were extracted from the trunk at breast height. In total, 157 trees ( 285 cores) were sampled. In the laboratory, the tree-ring samples were air-dried, after which they were fixed in wooden holders designed to hold the cores firmly, and they were then carefully polished with successively finer grits of sandpaper. The tree rings were visually cross-dated under a binocular microscope, and the ring widths were carefully measured using a LINTAB5 measuring system with a precision of $0.001 \mathrm{~mm}$. Cross-dating was verified using COFECHA software [24], which calculates correlation coefficients between individual tree-ring series as a way to identify absent or false rings. The cross-dated tree-ring data were detrended to remove the biological growth related to the tree's age and any other non-climate-related growth variation by fitting negative exponential or linear curves [25]. In a few cases, a cubic spline with a 50\% frequency response cutoff equal to two thirds of the series length was utilized when anomalous low-frequency growth trends occurred. These index series were then averaged to generate a standard (STD) chronology using the program ARSTAN [26]. In total, seven residual ring-width chronologies of Larix gmelinii were constructed and used in the subsequent analysis (Figure 3).

Several commonly used descriptive statistics were calculated for comparisons among the chronologies. The standard deviation (SD) and the mean sensitivity (MS) were used to assess the high-frequency variations of the tree-ring chronologies [1], the first-order autocorrelation (AC1) was 
calculated to assess relationships with previous growth, and the signal-to-noise ratio (SNR) was calculated to evaluate the signal strength of the site chronologies [1]. The expressed population signal (EPS) was applied to measure the similarity between the finite-sample chronology and the theoretical population chronology based on an infinite number of trees. The threshold value for accepting an EPS value was set to 0.85 after Wigley et al. (1984) [27]. The mean series inter-correlation (RBAR) was used to evaluate the signal strength of each chronology, which is the mean correlation coefficient among the tree-ring series [22].

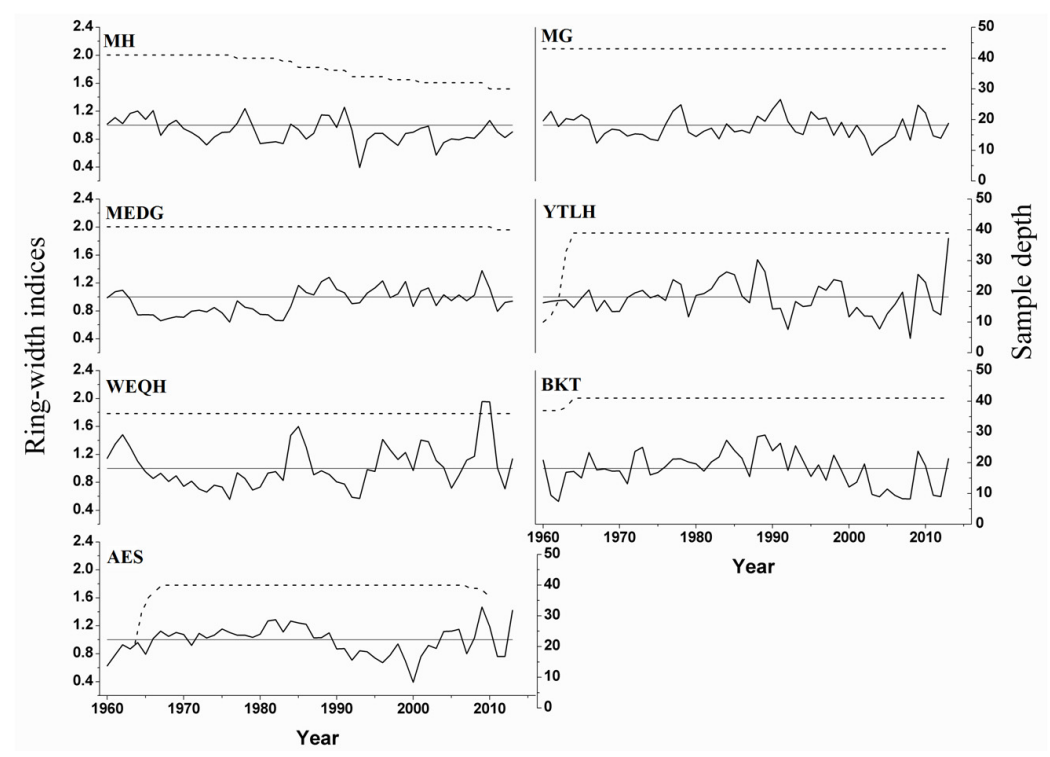

Figure 3. Ring-width residual chronologies for the period 1960-2013 constructed for Larix gmelinii along the latitudinal gradient from $47.27^{\circ}$ to $52.66^{\circ} \mathrm{N}$ at the seven sites (panels) in the Greater Khingan Mountains of the western Chinese boreal forest. The dashed lines indicate the numbers of tree-ring series.

\subsection{Climate Data}

There are only a few weather stations in the research area. Consequently, the climate observations for dendroclimatological investigations were insufficient. The climate data of research sites for analysis of growth-climate response were interpolated values on records that were randomly selected from 120 of 164 climate stations (120 stations across northeast China from Chinese Meteorological Data Sharing Service System [28] and 44 stations in Russia from Global Historical Climatology Network [29]).

The method of this interpolation is to fit a partial thin-plate smoothing spline model with location and elevation to ground-based observations for estimating a trend surface and then a simple kriging procedure is applied to the residuals for trend surface correction [30,31]. To evaluate the accuracy of interpolated values, a regression analysis was performed between interpolated and measured temperatures and precipitations at the remaining 44 climate stations. There was a good agreement with $R^{2}=0.99$.

Six climate variables were used for the dendroclimatological analyses, including monthly mean temperature ( $\mathrm{Tm})$, monthly minimum temperature (Tmin), monthly maximum temperature (Tmax), monthly total precipitation (Prec), annual mean temperature (Ta), and annual total precipitation (Prec).

\subsection{Climate-Growth Relationship Analysis}

The correlation analysis for climate and tree growth was performed using the response functions over a 17-month period (from June of the previous year to October of the current year of growth) [1]. The interval parameter was set to 1960-2013, which covered all of the tree-ring series. DENDROCLIM 2002 was used to carry out the statistical calculations [32]. 


\subsection{Definition of Regional Patterns}

Redundancy analysis (RDA) was used to analyze the regional responsive patterns of Larix gmelinii radial growth to environmental factors over the period 1960-2013. RDA is a multivariate "direct" gradient analysis that constrains its two tables of variables $X$ and $Y$ to represent linear combinations of supplied environmental factors [33]. RDA is a non-symmetric method in which the components extracted from $X$ are correlated as much as possible with the variables of $Y$, and then the components of $\mathrm{Y}$ are extracted with the aim of correlating them as much as possible with the components extracted from X. The correlation between abiotic and biotic variables is revealed by the cosine of the angle between two vectors in RDA biplots. Vectors pointing in the same direction show a high positive correlation, vectors pointing in opposite directions indicate a high negative correlation, and vectors crossing at right angles reveal a near-zero correlation [34]. The longer the vector, the more important the environmental parameter [33]. Each tree-ring chronological series within a site was treated as a sample, and each monthly response function was treated as a descriptor in this analysis [32]. For the statistical quantification of the similarity of the dendrochronological series, we calculated matrix correlation coefficients for the common period 1960-2013. The RDA was carried out for the seven chronologies pooled and the 42 climate variables over the common interval (1960-2013) using the program CANOCO (Version 4.5) [35].

\section{Results}

\subsection{Chronology Statistics}

Table 2 shows the dendrochronological characteristics of Larix gmelinii ring-width chronologies. The mean ring width ranged between 0.77 and $3.4 \mathrm{~mm}$. The mean sensitivity (MS) and standard deviation (SD) values ranged from 0.221 to 0.308 and from 0.143 to 0.321 , respectively, with the highest values at the middle latitudes (i.e., from WEQH to MEDG). For the analysis period of 1960-2013, the EPS of all the chronologies was higher than 0.85 . The high inter-series correlation, with values ranging between 0.504 and 0.665 , suggests that the chronologies recorded sufficient environmental signals.

Table 2. Statistical characteristics of Larix gmelinii residual chronologies along the latitudinal gradient from $47^{\circ}$ to $53^{\circ} \mathrm{N}$ in the western Greater Khingan Mountains, China.

\begin{tabular}{cccccccc}
\hline Site code & MH & MG & MEDG & YTLH & WEQH & BKT & AES \\
\hline SD & 0.178 & 0.275 & 0.321 & 0.229 & 0.278 & 0.145 & 0.143 \\
MS & 0.228 & 0.221 & 0.237 & 0.308 & 0.253 & 0.286 & 0.249 \\
AC1 & 0.528 & 0.590 & 0.580 & 0.680 & 0.610 & 0.460 & 0.790 \\
RBAR & 0.665 & 0.593 & 0.504 & 0.660 & 0.504 & 0.582 & 0.541 \\
EPS & 0.965 & 0.966 & 0.958 & 0.983 & 0.952 & 0.969 & 0.958 \\
PC1 & 0.369 & 0.410 & 0.390 & 0.628 & 0.280 & 0.460 & 0.730 \\
SNR & 27.355 & 28.646 & 22.785 & 56.848 & 20.012 & 30.782 & 23.089 \\
MRW (mm) & $0.77 \pm 0.2$ & $1.13 \pm 0.4$ & $0.67 \pm 0.2$ & $2.03 \pm 0.5$ & $0.68 \pm 0.4$ & $2.09 \pm 0.5$ & $3.4 \pm 0.4$ \\
No. of radii (trees) & $41(22)$ & $43(28)$ & $41(26)$ & $40(27)$ & $37(25)$ & $40(32)$ & $39(25)$ \\
Period & $1919-2014$ & $1902-2013$ & $1763-2013$ & $1941-2013$ & $1863-2013$ & $1939-2013$ & $1955-2013$ \\
\hline
\end{tabular}

SD, standard deviation; MS, mean sensitivity; AC1, first-order autocorrelation; RBAR, mean inter-series correlation; EPS, expressed population signal; PC1, percent variance explained by the first principal component; SNR, signal-to-noise ratio calculated for the standardized chronologies prior to autoregressive modeling; MRW, mean ring width.

\subsection{Radial Growth-Climate Associations}

Correlation coefficients between the tree-ring growth response of Larix gmelinii and the climatic variables were calculated to determine the significance of the climatic factors and the timing (Figure 4). In general, air temperature had a greater influence than the other climatic variations. Radial growth, as a whole, was negatively correlated with monthly mean temperatures (Tm) and monthly maximum temperatures (Tmax) in the current June at all latitudes, with significant correlations were found for 
stands at middle and low latitudes. Larix gmelinii radial growth across the latitudes was positively correlated with Tm and monthly minimum temperatures (Tmin) during current April to May, with significant correlations observed for AES, BKT and WEQH in May. In addition, radial growth was negatively correlated with current Tm and Tmin in February and March at most latitudes. Larix gmelinii radial growth across all latitudes was positively and negatively correlated with Tmin and Tmax, respectively, of the previous June, with significant correlations observed for AES, YTLH and MG/WEQH. In addition to the common growth response to climate across the gradient, site-specific growth responses to climate were also observed (Figure 4). For example, the radial growth of Larix gmelinii at AES was negatively influenced by the Tm of the previous December. In contrast, the WEQH and MEDG stands showed significant positive correlations with the September Tm of the previous year. Radial growth at MH and MG was significantly negatively correlated with Tm and Tmin in the current-year July. In addition, the radial growth at AES was also significantly positively and negatively correlated with Tmin in the current July and previous August, respectively.
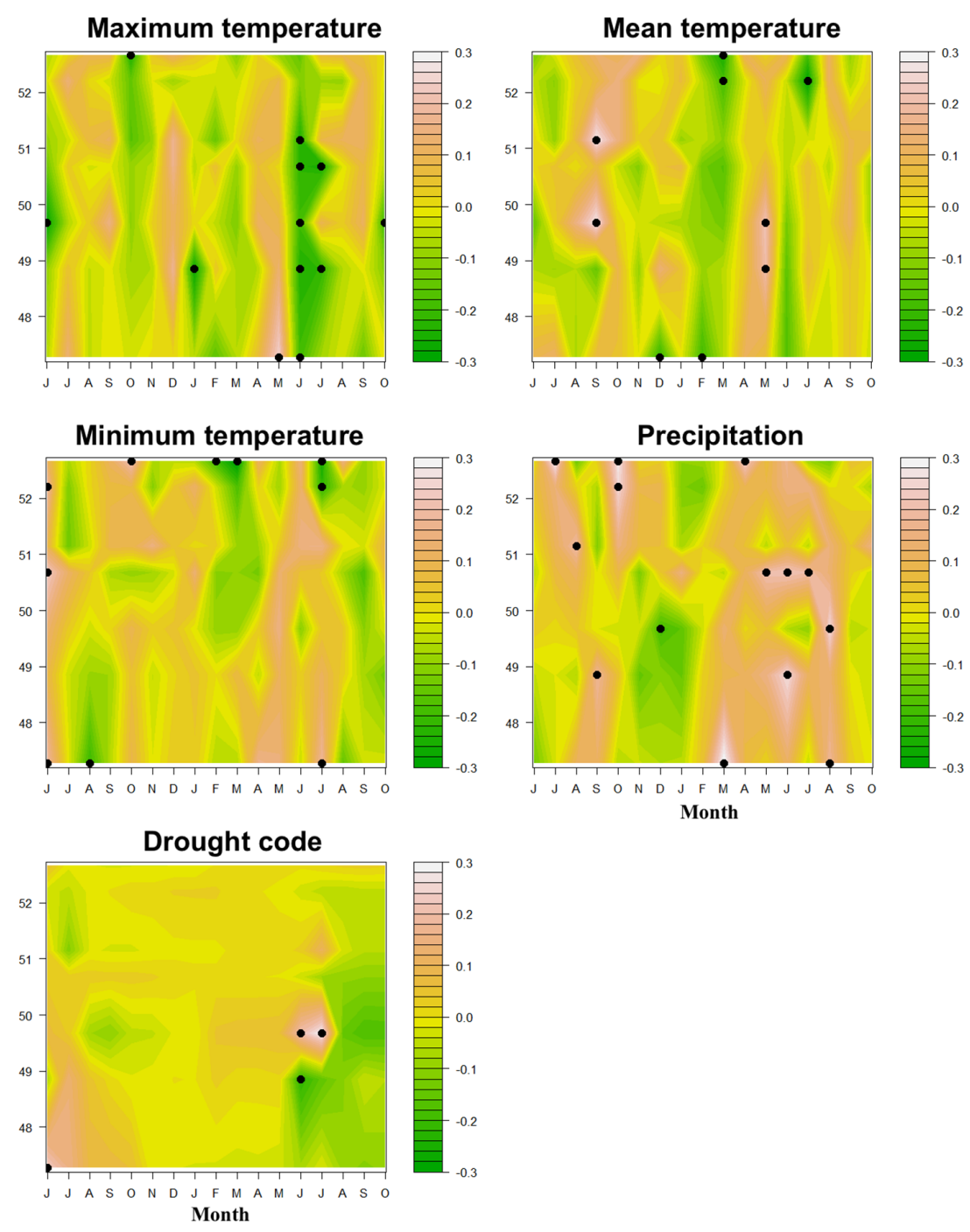

Figure 4. Bootstrapped correlation coefficients between Larix gmelinii residual tree-ring chronologies and the monthly climate variables (monthly maximum, mean, and minimum temperatures, monthly total precipitation, and monthly drought code) for the period 1960-2013 along the latitudinal gradient from $47.27^{\circ}$ to $52.66^{\circ} \mathrm{N}$ in the boreal forest of the western Greater Khingan Mountains in Northeastern China. The black dots indicate significant correlations at the $p<0.05$ level. 
Precipitation also had a significant influence on the radial growth of Larix gmelinii (Figure 4). At almost all latitudes, the positive correlation was observed between radial growth and precipitation during March to August of the current year and summer to autumn of the previous year. However, the correlation was negative for the winter of the previous year. The radial growth was significantly and positively correlated with the current year's PDSI in the current June-July at WEQH, and a significantly negative correlation was observed in the current June at BKT.

\subsection{Spatial Patterns of Climate-Growth Responses}

In terms of climate, the dendrochronological series could be separated into three groups in the RDA (Figure 5). The first group of series correlated positively with Ta; this group comprised the sites located south of $49^{\circ} \mathrm{N}$ (low-latitude region). The second group of the dendrochronological series (MG and $\mathrm{MH}$ ), at latitudes higher than $52^{\circ} \mathrm{N}$ and situated in the high latitudes of the region, showed a significantly negative relationship with Ta. For the stands located in the middle latitudes of the region (from $49^{\circ}$ to $51^{\circ} \mathrm{N}$, i.e., WEQH, YTLH, and MEDG), the importance of local factors (e.g., soil N content, slope, soil depth) increased.

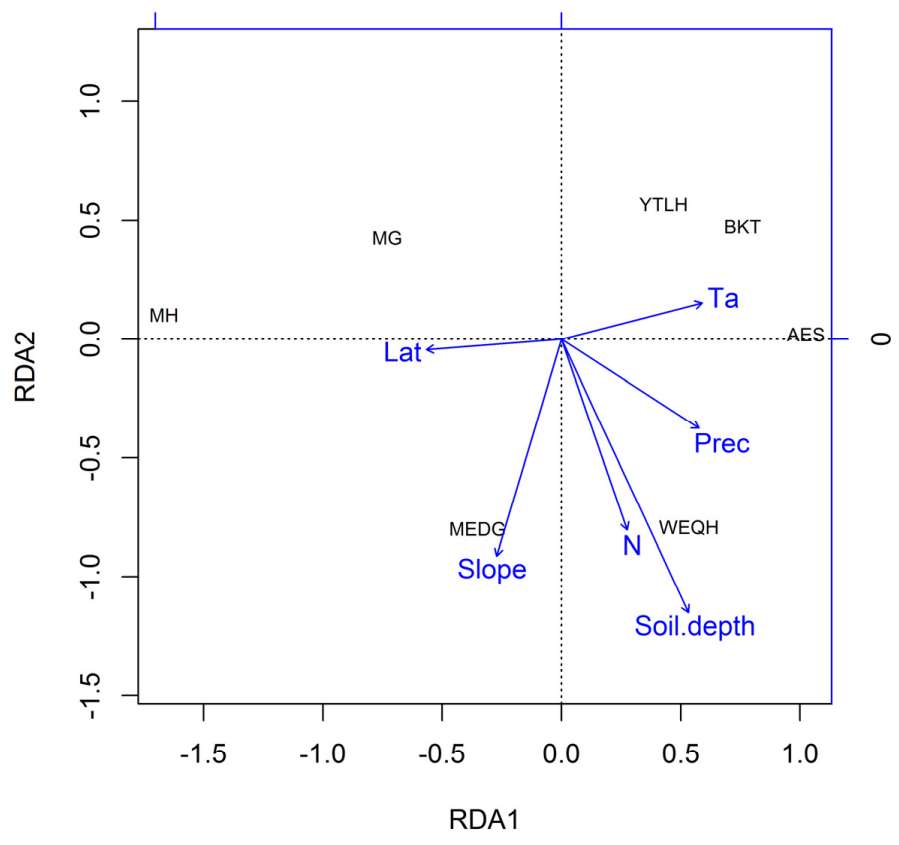

Figure 5. Redundancy analysis (RDA) calculated from the seven residual chronologies, local factors, and the monthly climate parameters for the period 1960-2013. Significant $(p<0.05)$ environmental factors are indicated by vectors (blue arrows); the longer the vector, the more important the climate parameter. The correlation between the variables is illustrated by the cosine of the angle between two vectors. Vectors at sharp angles indicate a positive correlation, vectors at obtuse angles indicate a negative correlation, and vectors crossing at right angles indicate a near-zero correlation [33]. $\mathrm{Ta}=$ annual mean temperature, Prec = annual total precipitation, $\mathrm{N}=$ soil organic nitrogen content. Slope $=$ the slope of the sampling point, Soil depth = the depth of the soil layer at the sampling point, Lat = the latitude of the sampling point. MH, MG, MEDG, YTLH, WEQH, BKT, and AES represent the seven sampling sites (i.e., Mohe, Mangui, Moerdaoga, Yitulihe, Wuerqihan, Boketu, and Aershan, respectively).

To verify whether the spatial patterns of the radial growth response to climate varied with latitude, a correlation coefficient matrix among the studied chronologies was calculated and analyzed (Table 3). The results revealed a high correlation in the dendrochronological series between neighboring latitudes. The highest correlation was that between MEDG and WEQH, while the lowest correlation was that 
between MH and AES (Table 3). Furthermore, we found two relatively high correlations; one was the series from latitudes lower than $49^{\circ} \mathrm{N}$; the other was the series from latitudes higher than $52^{\circ} \mathrm{N}$. The RDA (Figure 5) and correlation coefficient matrix (Table 3) revealed that the radial growth of L. gmelinii followed three variation models corresponding to the three latitude levels (low: lower than $49^{\circ} \mathrm{N}$; middle: $49^{\circ} \mathrm{N}$ to $51^{\circ} \mathrm{N}$; high: higher than $52^{\circ} \mathrm{N}$ ).

Table 3. Correlation matrix for the standard ring-width chronologies for the seven sampling sites, 1960-2013 (all values significant at $p<0.05$ ).

\begin{tabular}{cccccccc}
\hline & AES & BKT & WEQH & YTLH & MEDG & MG & MH \\
\hline AES & 1 & 0.46 & 0.44 & 0.43 & 0.26 & 0.06 & 0.01 \\
BKT & & 1 & 0.31 & 0.63 & 0.36 & 0.36 & 0.23 \\
WEQH & & & 1 & 0.52 & 0.68 & 0.44 & 0.26 \\
YTLH & & & & 1 & 0.39 & 0.46 & 0.21 \\
MEDG & & & & & 1 & 0.39 & 0.29 \\
MG & & & & & & 1 & 0.63 \\
MH & & & & & & & 1 \\
\hline
\end{tabular}

\section{Discussion}

Dendroecological and dendroclimatological methods were used to analyze the climate-growth relationships for Larix gmelinii stands in the western Greater Khingan Mountains of China. In the past few decades, large-spatial-scale studies of tree species have been conducted at mid- to high latitudes of the Northern Hemisphere. For example, in the eastern Canadian boreal forest, Jianguo Huang explored the responses of four major boreal tree species to climatic variations along a broad latitudinal gradient and concluded that the growth of Betula papyrifera stands located north of $49^{\circ} \mathrm{N}$ and the growth of P. mariana and P. banksiana stands north of $47^{\circ} \mathrm{N}$ were positively correlated with winter and spring temperatures, whereas the growth of stands at more southerly latitudes was negatively correlated with winter and spring temperatures [8]. In Central and Northern Europe, Mäkinen reported that the effect of low temperatures on tree radial growth was more significant at northern sites, while the relative importance of precipitation was greater for the southern sites [36]. Lloyd investigated the climate response of three Siberian taiga species, Picea obovata, Larix cajanderi, and Pinus sylvestris across a latitudinal gradient in central Siberia and concluded that climate response varied among and within populations of all species, and positive responses to temperature prevailed at northern sites, where trees grew faster in years with warm early summers. Negative responses to warming declined along the south to north latitudinal gradient [37].

In the current study, the redundancy analysis (RDA) and correlation analysis revealed that Larix gmelinii exhibited some consistent radial growth-climate associations across the latitudes (Figure 4, Figure 5). Temperatures during the current June to July proved to be the most important environmental factor affecting the radial growth of Larix gmelinii at the regional scale. Meanwhile, in China, the increase of summer temperatures is most significant in the northeast [19]. Our results indicate that higher monthly maximum temperatures (Tmax) in the current June may increase water stress, limiting the radial growth of Larix gmelinii across the gradient, and that serious growth inhibition occurred at the mid- and low-latitude sites. Our results also suggest that a warmer June monthly minimum temperatures (Tmin) in the previous year favored radial growth in the current growing season across the gradient, especially at AES, YTLH, and MG. The highest precipitation in our study region occurs in summer, and a warmer June Tmin most likely enhances photosynthetic rates and accelerates radial growth [38]. At the same time, more sugars are stored in tree biomass over the winter, which are available for tree growth in the following summer [39]. However, hot summer temperatures might enhance stand respiration and evapotranspiration, thus resulting in increased water deficits $[8,40]$ that limit the growth of Larix gmelinii. In addition, warm July temperatures in the current year can significantly limit the radial growth of Larix gmelinii north of $52^{\circ} \mathrm{N}$. The inhibition of radial growth at 
higher latitudes by warm July temperatures may be due to the low precipitation and/or shallowness of the soil in this region. In addition, these sites have sandy soils, likely resulting in low soil water-holding capacity, so that the warmer temperature will cause a soil water deficit at these latitudes. This supports the findings of Wang [21], who also documented negative relationships between Larix gmelinii radial growth and the current-year July temperatures in this area.

Current-year February-March monthly mean temperatures (Tm) and monthly minimum temperatures (Tmin) were found to negatively affect the radial growth of Larix gmelinii across latitudes, particularly at MH and MG (high latitudes) and AES (low latitude). Our results are consistent with those of Wang [19], who also observed that the temperature in the previous November and December and in the March of the current year had a negative effect on the growth of Larix gmelinii at $\mathrm{MH}$. Tree-ring radial growth is known to be influenced by the amount of storage compounds and the current soil moisture regime [41]. This is likely due to warmer winter (December-February) temperatures, which increase the loss of carbohydrates stored for growth in the following summer [42]. More detailed investigation on the influence of late-winter and early-spring temperatures on radial growth is needed to gain a deeper understanding of the relationship between radial increment and climatic variation.

The warm Tm in April-May was favorable for Larix gmelinii radial growth at all sites, especially favoring radial growth at BKT and WEQH. Warm spring temperatures can result in early leaf emergence or budburst and thus result in better growth due to an extended growing season. Graumlich reported that warm temperatures in April may favor coniferous species because their evergreen foliage allows them to take advantage of the warmth during the early growing season [43]. Similarly, Suni emphasized the significance of air temperature triggering the initiation of photosynthesis in boreal conifers in spring [44]. Goodine further noted the particular importance of spring air temperature for tree species whose root systems grow in frozen soils to trigger the initiation of photosynthesis because for tree species whose root systems extend below the frost line, the onset of photosynthesis may be triggered by soil thawing [38]. More unfrozen soil water could be present because of the warm spring air temperatures that are necessary for the onset of photosynthesis. The photosynthetic rate of well-watered foliage may also be favored by higher air temperatures [38]. Our results are in line with those of Wang [21], who suggested that Larix gmelinii radial growth at high latitudes $\left(52^{\circ} \mathrm{N}\right.$ to $53^{\circ} \mathrm{N}$ ) was positively correlated with air temperature during the current-year April to May. The radial growth of Larix gmelinii at the mid-latitude sites (especially MEDG and WEQH) was significantly and positively affected by Tm in the previous autumn. However, at the low- and high-latitude sites, a warmer autumn Tm clearly resulted in a prolonged growing season, which led to enhanced growth of L. gmelinii.

Our results suggested that precipitation was also an important factor limiting the radial growth in the Greater Khingan Mountains. At almost all latitudes, the growth of Larix gmelinii was limited by water availability, as suggested by the significant positive correlation between radial growth and precipitation during the current March to August and the previous June to October. As water supply during the spring season is crucial for tree growth, sufficient accumulation of snow and the consequent melting may meet the water demands of Larix gmelinii stands during an early growing season [45]. Summer precipitation has a direct influence on the tree-ring increment because rain is used to almost immediately recharge the soil water reservoir. Low summer precipitation may cause water stress and reduced photosynthesis [46]. The correlation between ring width and summer precipitation in mid-high Northern Hemisphere sites is predominantly positive [47]. In line with this, the ring width in this study was significantly positively correlated with summer precipitation across most of the latitudes in the Greater Khingan Mountains, but at WEQH (mid-latitude), the association with summer precipitation was negative. A possible reason is that on the steep slopes, considerable amounts of soil nutrients are washed out by the high summer precipitation. Ring-width correlations with precipitation during the growing season at northern MEDG were non-significant and were weaker than those for the southern latitudes. This might be because the relative importance of precipitation during the 
growing season increased in the warmer southern region. This study revealed that wet winters have a relatively weak negative impact on ring widths at almost all latitudes. A possible reason for this may be that deep snow during winter could delay snow-melt and limit tree growth [48]. Our results are in line with those of Wang [19], who showed that the radial growth of Larix gmelinii from $52^{\circ} \mathrm{N}$ to $53^{\circ} \mathrm{N}$ was negatively correlated with winter precipitation because precipitation from the previous winter was important for bud protection. Li reported that the summer and autumn precipitation in Northeastern China has decreased since the 1960s [49]; thus, precipitation's limiting effect increases for Larix gmelinii growth. Based on the findings in this study, rapid warming and drying were not conducive to L. gmelinii growth in the Greater Khingan Mountains. This is consistent with the results that have suggested that L. gmelinii in the Greater Khingan Mountains would be replaced by other species [16-18].

\section{Conclusions}

Temperatures during current June to July were found to be the dominant environmental factor affecting the radial growth of Larix gmelinii in the Greater Khingan Mountains. More specifically, Larix gmelinii growth might be decreasing in radial growth by higher Tmax in June, especially in the stands at low and middle latitudes. Larix gmelinii radial growth at high latitudes (MG and MH) might be reduced by warmer temperatures in July. Meanwhile, precipitation was also an important factor limiting the radial growth at the regional scale. Larix gmelinii might be decreasing in radial growth from decreasing precipitation occurring across the gradient. Our results show that there is a decreasing trend in Larix gmelinii radial growth under the observed general increase of temperature in the Greater Khingan Mountains in recent years.

Acknowledgments: The research was funded by The National Key Research and Development Program of China (2016YFA0600804) and the National Natural Science Foundation of China (Nos. 41575153, 41330530 and 41430639).

Author Contributions: Y.J., J.Z. and S.H. conceived and designed the experiments; Y.J., Y.G. and Y.T. performed the experiments; Y.J., J.Z. and S.H. analyzed the data; J.Z., S.H., Z.J., H.S., X.B. and J.Y. contributed reagents/materials/analysis tools; Y.J. wrote the paper.

Conflicts of Interest: The authors declare no conflict of interest.

\section{References}

1. Fritts, H.C. Tree Rings and Climate; Academic Press: New York, NY, USA, 1976.

2. Zhang, X.; Chen, Z. A new method to remove the tree growth trend based on ensemble empirical mode decomposition. Trees 2015, 1-9. [CrossRef]

3. Liang, E.Y.; Shao, X.M.; Eckstein, D.; Liu, X. Spatial variability of tree growth along a latitudinal transect in the Qilian Mountains, northeastern Tibetan Plateau (EI). Can. J. For. Res. 2010, 40, 200-211. [CrossRef]

4. Yu, D.; Wang, Q.; Wang, Y.; Zhou, W.; Ding, H.; Fang, X.; Dai, L. Climatic effects on radial growth of major tree species on Changbai Mountain. Ann. For. Sci. 2011, 68, 921-933. [CrossRef]

5. Thuiller, W.; Lavorel, S.; Arujo, M.B.; Sykes, M.T.; Prentice, I.C. Climate change threats to plant diversity in Europe. Proc. Natl. Acad. Sci. 2005, 102, 8245-8250. [CrossRef] [PubMed]

6. Tardif, J.C.; Conciatori, F.; Nantel, P.; Gagnon, D. Radial growth and climate responses of white oak (Quercus alba) and northern red oak (Quercus rubra) at the northern distribution limit of white oak in Quebec, Canada. J. Biogeogr. 2006, 33, 1657-1669. [CrossRef]

7. Metsaranta, J.M.; Lieffers, V.J.; Wein, R.W. Dendrochronological reconstruction of jack pine snag and downed $\log$ dynamics in Saskatchewan and Manitoba, Canada. For. Ecol. Manag. 2008, 255, 1262-1270. [CrossRef]

8. Huang, J.; Tardif, J.C.; Bergeron, Y.; Denneler, B.; Berninger, F.; Girardin, M.P. Radial growth response of four dominant boreal tree species to climate along a latitudinal gradient in the eastern Canadian boreal forest. Glob. Chang. Biol. 2010, 16, 711-731. [CrossRef]

9. Wang, X.M.; Zhao, X.H.; Gao, L.S. Climatic response of Betula ermanii along an altitudinal gradient in the northern slope of Changbai Mountain, China. Dendrobiology 2013, 70, 99-107. [CrossRef] 
10. Peng, X.; Xiao, S.; Cheng, G.; Xiao, H.; Tian, Q.; Zhang, Q. Human activity impacts on the stem radial growth of Populus euphratica, riparian forests in China's Ejina oasis, using tree-ring analysis. Trees 2015, 1-14. [CrossRef]

11. Griesbauer, H.P.; Green, D.S. Geographic and temporal patterns in white spruce climate-growth relationships in Yukon, Canada. For. Ecol. Manag. 2012, 267, 215-227. [CrossRef]

12. Li, Z.; Liu, G.; Fu, B.; Zhang, Q.; Ma, K.; Pederson, N. The growth-ring variations of alpine shrub Rhododendron przewalskii reflect regional climate signals in the alpine environment of Miyaluo town in western Sichuan province, China. Acta Ecol. Sinica 2013, 33, 23-31. [CrossRef]

13. Zyryanova, O.A.; Yaborov, V.T.; Tchikhacheva, T.L.; Koike, T.; Makoto, K.; Matsuura, Y.; Zyryanov, V.I. The structure and biodiversity after fire disturbance in Larix gmelinii (Rupr.). Eurasian J. For. Res. 2007, 10, 19-29.

14. Farjon, A. Pinaceae; Koeltz Scientific Books: Konigstein, Germany, 1990.

15. Fu, L.K.; Li, N.; Mill, R.R. Larix. In Flora of China; Wu, Z.Y., Raven, P.H., Eds.; Science Press: Beijing, China; Missouri Botanical Garden Press: St. Louis, MI, USA, 1999; pp. 33-37.

16. Cheng, X.X.; Yan, X.D. Effects of global climate change on forest succession in Daxing'anling of Northeast China. Chin. J. Ecol. 2007, 26, 1277-1284. (In Chinese)

17. Leng, W.F.; He, H.S.; Bu, R.C.; Hu, Y.M. Sensitivity analysis of the impacts of climate change on potential distribution of three larch (Larix) species in northeastern China. J. Plant Ecol. 2007, 31, 825-833. (In Chinese)

18. Cheng, X.X.; Yan, X.D. Effects of climate change on typical forest in the northeast of China. Acta Ecol. Sinica. 2008, 28, 534-543. (In Chinese)

19. Qian, W.; Qin, A. Spatial-temporal characteristics of temperature variation in China. Meteorol. Atmos. Phys. 2006, 93, 1-16. [CrossRef]

20. Wang, L.; Shao, X.; Huang, L.; Liang, E. Tree-ring characteristics of Larix gmelinii and Pinus sylvestris var. Mongolica and their response to climate in Mohe, China. Chin. J. Plant Ecol. 2005, 29, 380-385. (In Chinese) [CrossRef]

21. Wang, X.; Zhang, Y.; Mcrae, D.J. Spatial and age-dependent tree-ring growth responses of Larix gmelinii to climate in northeastern China. Trees 2009, 23, 875-885. [CrossRef]

22. Zhang, X.; Bai, X.; Chang, Y.; Chen, Z. Increased sensitivity of Dahurian larch radial growth to summer temperature with the rapid warming in Northeast China. Trees 2016, 1-8. [CrossRef]

23. Hutchinson, M.F. ANUSPLIN Version 4.3. Center for Resource and Environmental Studies, Australian National University: Canberra, Australia, 2004. Available online: http://fennerschool.anu.edu.au/ publications/software/anusplin.php (accessed on 12 December 2008).

24. Holmes, R.L. Computer-assisted quality control in tree-ring dating and measurement. Tree-Ring Bull. 1983, $44,69-75$.

25. Cook, E.R.; Briffa, K.R. Data analysis. In Methods of Dendrochronology; Cook, E.R., Kairiukstis, L.A., Eds.; Kluwer: Boston, MA, USA, 1990; pp. 97-162.

26. Cook, E.R. A time series approach to tree-ring standardization. Ph.D. Thesis, University of Arizona, Tucson, AZ, USA, 1985.

27. Wigley, T.M.L.; Briffa, K.R.; Jones, P.D. On the average value of correlated time series, with applications in dendroclimatology and hydrometeorology. J. Clim. Appl. Meteorol. 1984, 23, 201-213. [CrossRef]

28. Chinese Meteorological Data Sharing Service System. Available online: http://www.cma.gov.cn (accessed on 16 September 2015).

29. Global Historical Climatology Network. Available online: https://www.ncdc.noaa.gov (accessed on 20 September 2015).

30. Huang, C.; Zheng, X.; Tait, A.; Dai, Y.; Yang, C.; Chen, Z.; Wang, Z. On using smoothing spline and residual correction to fuse rain gauge observations and remote sensing data. J. Hydrol. 2013, 508, 410-417. [CrossRef]

31. Li, T.; Zheng, X.; Dai, Y.; Yang, C.; Chen, Z.; Zhang, S.; Liao, R. Mapping near-surface air temperature, pressure, relative humidity and wind speed over Mainland China with high spatiotemporal resolution. Adv. Atmos. Sci. 2014, 31, 1127-1135. [CrossRef]

32. Biondi, F.; Waikul, K. DENDROCLIM 2002: AC ++ program for statistical calibration of climate signals in tree-ring chronologies. Comput. Geosci. 2004, 30, 303-311. [CrossRef]

33. Legendre, P.; Legendre, L. Numerical Ecology; Elsevier Scientific: New York, NY, USA, 1998.

34. Braak, C.J.F.T.; Prentice, I.C. A theory of gradient analysis. Adv. Ecol. Res. 1988, 18, 271-317. [CrossRef] 
35. TerBraak, C.J.F.; Smilauer, P. CANOCO Reference Manual and Cano Draw for User's Guide Windows: Software for Canonical Community Ordination, Version 4.5. Microcomputer Power: Ithaca, NY, USA, 2002.

36. Mäkinen, H.; Nöjd, P.; Kahle, H.P.; Neumann, U.; Tveite, B.; Mielikäinen, K.; Spiecker, H. Radial growth variation of Norway spruce (Picea abies (L.) Karst.) across latitudinal and altitudinal gradients in central and northern Europe. For. Ecol. Manag. 2002, 171, 243-259. [CrossRef]

37. Lloyd, A.H.; Bunn, A.G.; Berner, L. A latitudinal gradient in tree growth response to climate warming in the Siberian taiga. Glob. Chang. Biol. 2010, 17, 1935-1945. [CrossRef]

38. Goodine, G.K.; Lavigne, M.B.; Krasowski, M.J. Spring time resumption of photosynthesis in balsam fir (Abiesbalsamea). Tree Physiol. 2008, 28, 1069-1076. [CrossRef] [PubMed]

39. LaMarche, V.C., Jr. Palecoclimatic inferences from long tree-ring records. Science 1974, 183, $1043-1048$. [CrossRef] [PubMed]

40. Zhang, X.; Cui, M.X.; Ma, Y.J.; Wu, T.; Chen, Z.J.; Ding, W.H. Larix gmelinii tree-ring width chronology and its responses to climate change in Kuduer, Great Xing'an mountains. Chin. J. Appl. Ecol. 2010, 21, 2501-2507.

41. Fritts, H.C.; Smith, D.G.; Cardis, J.W.; Budelsky, C.A. Tree-ring Characteristics along a vegetation gradient in northern Arizona. Ecology 1965, 46, 393-401. [CrossRef]

42. Su, H.; Axmacher, J.C.; Yang, B.; Sang, W. Differential radial growth response of three coexisting dominant tree species to local and large-scale climate variability in a subtropical evergreen broad-leaved forest of China. Ecol. Res. 2015, 30, 745-754. [CrossRef]

43. Graumlich, L.J. Response of tree growth to climatic variation in the mixed conifer and deciduous forest of the upper Great Lakes region. Can. J. For. Res. 1993, 23, 133-143. [CrossRef]

44. Suni, T.; Berninger, F.; Vesala, T. Air temperature triggers the recovery of evergreen boreal forest photosynthesis in spring. Glob. Chang. Biol. 2003, 9, 1410-1426.

45. Savva, Y.; Bergeron, Y.; Denneler, B.; Koubaa, A.; Tremblay, F. Effect of interannual climate variations on radial growth of jack pine provenances in Petawawa, Ontario. Can. J. For. Res. 2008, 38, 619-630. [CrossRef]

46. Butt, N.; Bebber, D.P.; Riutta, T.; Crockatt, M.; Morecroft, M.D.; Malhi, Y. Relationships between tree growth and weather extremes: Spatial and interspecific comparisons in a temperate broadleaf forest. For. Ecol. Manag. 2014, 334, 209-216. [CrossRef]

47. George, S.S.; Ault, T.R. The imprint of climate within Northern Hemisphere trees. Quat. Sci. Rev. 2014, 89, 1-4. [CrossRef]

48. Vaganov, E.A.; Hughes, M.K.; Kirdyanov, A.V.; Schweingruber, F.H.; Silkin, P.P. Influence of snowfall and melt timing on tree growth in subarctic Eurasia. Nature 1999, 400, 149-151.

49. Li, B.; Zhou, X.; Zhao, Z.; Wang, J.; Wang, S.; Shang, K.; Li, P. Change features of different types and grades of precipitation event in northeast China in recent 50 years. Plateau Meteorol. 2013, 32, 1414-1424. (In Chinese) 